\title{
Preparation and Characterization of Salt-Mediated Injectable Thermosensitive Chitosan/Pectin Hydrogels for Cell Embedding and Culturing
}

\author{
Giulia Morello ${ }^{1,2,+}{ }^{\text {, Alessandro Polini }}{ }^{2, *}++^{(D}$, Francesca Scalera ${ }^{2} \mathbb{D}$, Riccardo Rizzo ${ }^{2}$, Giuseppe Gigli ${ }^{1,2}$ \\ and Francesca Gervaso ${ }^{2, *}$
}

Citation: Morello, G.; Polini, A.; Scalera, F.; Rizzo, R.; Gigli, G.; Gervaso, F. Preparation and Characterization of Salt-Mediated Injectable Thermosensitive

Chitosan/Pectin Hydrogels for Cell Embedding and Culturing. Polymers 2021, 13, 2674. https://doi.org/ $10.3390 /$ polym 13162674

Academic Editors: Elia Marin,

Francesco Boschetto,

Alfredo Rondinella and Faisal Raza

Received: 21 July 2021

Accepted: 8 August 2021

Published: 10 August 2021

Publisher's Note: MDPI stays neutra with regard to jurisdictional claims in published maps and institutional affiliations.

Copyright: (c) 2021 by the authors. Licensee MDPI, Basel, Switzerland. This article is an open access article distributed under the terms and conditions of the Creative Commons Attribution (CC BY) license (https:// creativecommons.org/licenses/by/ $4.0 /)$.
1 Dipartimento di Matematica e Fisica E. De Giorgi, University of Salento, Campus Ecotekne, via Monteroni, 73100 Lecce, Italy; giulia.morello@unisalento.it (G.M.); giuseppe.gigli@unisalento.it (G.G.)

2 CNR NANOTEC - Institute of Nanotechnology c/o Campus Ecotekne, via Monteroni, 73100 Lecce, Italy; francesca.scalera@nanotec.cnr.it (F.S.); riccardo.rizzo@nanotec.cnr.it (R.R.)

* Correspondence: alessandro.polini@nanotec.cnr.it (A.P.); francesca.gervaso@nanotec.cnr.it (F.G.); Tel.: +39-0832-319305(A.P. \& F.G.)

$+\quad$ These authors equally contributed to this study.

\begin{abstract}
In recent years, growing attention has been directed to the development of 3D in vitro tissue models for the study of the physiopathological mechanisms behind organ functioning and diseases. Hydrogels, acting as 3D supporting architectures, allow cells to organize spatially more closely to what they physiologically experience in vivo. In this scenario, natural polymer hybrid hydrogels display marked biocompatibility and versatility, representing valid biomaterials for 3D in vitro studies. Here, thermosensitive injectable hydrogels constituted by chitosan and pectin were designed. We exploited the feature of chitosan to thermally undergo sol-gel transition upon the addition of salts, forming a compound that incorporates pectin into a semi-interpenetrating polymer network (semi-IPN). Three salt solutions were tested, namely, beta-glycerophosphate ( $\beta G P$ ), phosphate buffer (PB) and sodium hydrogen carbonate (SHC). The hydrogel formulations (i) were injectable at room temperature, (ii) gelled at $37^{\circ} \mathrm{C}$ and (iii) presented a physiological $\mathrm{pH}$, suitable for cell encapsulation. Hydrogels were stable in culture conditions, were able to retain a high water amount and displayed an open and highly interconnected porosity and suitable mechanical properties, with Young's modulus values in the range of soft biological tissues. The developed chitosan/pectin system can be successfully used as a 3D in vitro platform for studying tissue physiopathology.
\end{abstract}

Keywords: natural polymers; thermoresponsive hydrogels; semi-IPN system; 3D in vitro models; cell encapsulation

\section{Introduction}

In recent years, scientific research has focused its attention on the development of three-dimensional (3D) in vitro tissue models, used in various research areas such as drug development and precision medicine [1,2]. Three-dimensional culture models, mimicking biological tissues' architecture and microenvironment, can be very useful for studying several disease-related mechanisms such as tumor onset, progression and metastasis [3]. Ideally, a 3D tissue model should faithfully reproduce the typical cellular architecture of the native tissue and provide a network of molecules that play a key role in disease progression $[4,5]$. The importance of suitable 3D in vitro models is strictly linked to the need to bridge the gap between traditional 2D cell cultures and animal models used in scientific research [6]. Although 2D cultures have been and are still widely employed to study various diseases, they have a poor ability in reproducing the physiological tissue architecture [7]. On the other hand, although animal models have undoubted advantages over in vitro cultures, the experimental costs, ethical concerns and species variability often do not allow 
for the extension of therapies to humans [8]. In order to obtain physiologically relevant 3D systems to be successfully used to study pathological mechanisms, hydrogels are promising candidates thanks to their versatility and tailoring possibilities. Polymeric hydrogels are cross-linked macromolecular networks widely used for several biomedical applications, ranging from tissue engineering to drug delivery [9]. In 3D in vitro cultures, hydrogels facilitate the interaction and exchange of metabolites between cells and the matrix [10] and, acting as a "scaffold," allow cells to self-organize in vitro similarly to what occurs in vivo. Hydrogel systems can be classified into natural, synthetic or hybrid hydrogels depending on their composition. Natural hydrogels are biocompatible, biodegradable and, being very similar to the native tissue extracellular matrix (ECM) from a physiochemical point of view, able to interact with living cells, while synthetic systems are generally inert, are not biodegradable and, consequently, do not allow a proper matrix remodeling [11]. Natural hydrogels include polysaccharides, proteins and animal derivatives, all being extensively used for cell culture studies. However, their low mechanical properties and poor stability, generally related to the physical cross-linking mechanism, limit their use for long-term culture [12]. In order to improve the performance of single-polymer hydrogels, hybrid hydrogels, composed of two different polymers, can be developed that present more controlled physicochemical properties [13]. Among hybrid hydrogels made of natural polymers, chitosan/pectin systems have recently been proposed for tissue engineering applications and drug delivery systems $[14,15]$. Chitosan, a deacetylated derivative of chitin, is a cationic polysaccharide, localized in the exoskeleton of crustaceans [16]. It is highly biodegradable and biocompatible and also shows interesting wound-healing, anti-microbial and anti-tumor properties [17-19]. Pectin, a linear, non-toxic, anionic plant polysaccharide, is characterized by the presence of galacturonic acid molecules and is widely used for biomedical applications $[20,21]$. Though Pec/Ch systems have already been proposed for cell culture, their combined use to prepare an injectable thermosensitive hydrogel suitable for cell embedding and culturing has not been reported yet.

As reported in the literature, chitosan interacts with salt solutions, such as betaglycerophosphate $(\beta \mathrm{GP})$, for obtaining thermosensitive hydrogels at physiological conditions [22-24]. In this study, we exploited such $\mathrm{Ch}$ feature to form a hybrid compound by incorporating a second polymer, pectin, allowing greater flexibility without altering the system stability. Three weak bases were tested, namely, $\beta$ GP, phosphate buffer (PB) and sodium hydrogen carbonate (SHC), already used in the literature for their ability to raise the $\mathrm{pH}$ of acidic Ch solutions up to physiological values and induce a sol-gel transition at the physiological temperature [22,25]. All the obtained hydrogels were characterized in terms of $\mathrm{pH}$ measurement, injectability, thermosensitive sol-gel transition, swelling properties, in vitro stability, morphology and cell viability. Rheometer analysis was performed to evaluate the rheological properties of the system, and FT-IR analysis was carried out to outline the nature of the interactions between the polymer chains and the gelling agents. Finally, the potential of the hydrogels as 3D in vitro systems for cell embedding and culturing was also investigated by preliminary biological tests, performed to evaluate the viability of a colon rectal cancer cell line (HCT 116) embedded into the systems.

\section{Materials and Methods}

\subsection{Preparation of Chitosan/Pectin Hybrid Hydrogels}

Low-molecular weight chitosan (Ch) (\#448869, Sigma Aldrich, Milan, Italy) and pectin (Pec) from citrus peel (galacturonic acid $\geq 74.0 \%$ dried basis) (\#P9135, Sigma Aldrich, Milan, Italy) were used for hydrogel preparation. Hydrogels were prepared by solubilizing $\mathrm{Ch}$ powder $3.33 \%(w / v)$ in $0.1 \mathrm{M}$ hydrochloric acid $(\mathrm{HCl})$ solution and Pec powder $3.33 \%$ $(w / v)$ in ultrapure Milli-Q water under stirring at room temperature (r.t.) overnight. The concentration of the starting polymer solution was selected after preliminary tests, aimed at obtaining the most concentrated polymer $(\mathrm{Ch})$ solution by stirring at room temperature (i.e., avoiding high temperatures) and using a low $\mathrm{HCl}$ molarity. The gelling agent (GA) solutions were prepared by dissolving $\beta \mathrm{GP}, \mathrm{PB}$ and SHC powders in Milli-Q water to a final 
concentration of $0.04 \mathrm{M}$ (see Table 1). The two polymer solutions, previously centrifuged at $1500 \mathrm{rpm}$ for $5 \mathrm{~min}$ at $4{ }^{\circ} \mathrm{C}$, were mixed in an optimized ratio (50:50), and the resulting mix Ch-Pec with $\mathrm{pH} 6.00$ was stored at $4{ }^{\circ} \mathrm{C}$ until use. For hydrogel preparation, the three GA solutions, $\beta \mathrm{GP}, \mathrm{PB}$ and $\mathrm{SHC}$, were alternately added to the Ch-Pec mix in the optimized volume ratio of 5:1 (Ch-Pec mix/GA solution) using two syringes joined by a Luer-lock connector and then centrifuged at $1500 \mathrm{rpm}$ for $2 \mathrm{~min}$ at r.t. The pre-hydrogel solutions were then incubated at $37^{\circ} \mathrm{C}$ for $2 \mathrm{~h}$, in order to thermally induce the sol-gel transition, with or without the drop-by-drop addition of $500 \mu \mathrm{L}$ of Dulbecco's Modified Eagle Medium (DMEM) to simulate cell encapsulation.

Table 1. Initial and final polymer and GA solution concentrations. $\mathrm{pH}$ values of $\mathrm{Ch}$ and Pec solutions, gelling agent, $\mathrm{Ch}-\mathrm{Pec}$ mix and final hydrogels. $V_{i}=$ initial volume.

\begin{tabular}{|c|c|c|c|c|}
\hline $\begin{array}{l}\text { Polymer and Solution } \\
\text { Concentrations }\end{array}$ & Initial Concentration & Initial pH Value & Final pH Value & Final Concentration \\
\hline $\mathrm{Ch}$ in $0.1 \mathrm{M} \mathrm{HCl}$ & $3.33 \%$ & 6 & - & $1.38 \%$ \\
\hline Pec in H20 D.I. & $3.33 \%$ & 5 & - & $1.38 \%$ \\
\hline $\mathrm{Ch}-\mathrm{Pec}$ & - & - & 6 & $2.77 \%$ \\
\hline Ch-Pec- $\beta$ GP (0.04 M) & - & - & 7 & - \\
\hline Ch-Pec- $\beta$ GP $(0.08 \mathrm{M})$ & - & - & $7.0 / 8.0$ & - \\
\hline Ch-Pec- $\beta$ GP (0.16 M) & - & - & $7.0 / 8.0$ & - \\
\hline Ch-Pec-PB (0.04 M) & - & - & $6.0 / 7.0$ & - \\
\hline Ch-Pec-SHC (0.04 M) & - & - & 8 & - \\
\hline Ch-Pec- $\beta$ GP-DMEM & - & - & $7.0 / 8.0$ & - \\
\hline Ch-Pec-PB-DMEM & - & - & $7.0 / 8.0$ & - \\
\hline Ch-Pec-SHC-DMEM & - & - & 8 & - \\
\hline$\beta G P$ & $0.1 \mathrm{M}\left(\mathrm{V}_{\mathrm{i}}=1.2 \mathrm{~mL}\right)$ & $8.0 / 9.0$ & - & $0.04 \mathrm{M}$ \\
\hline$\beta G P$ & $0.2 \mathrm{M}\left(\mathrm{V}_{\mathrm{i}}=1.2 \mathrm{~mL}\right)$ & - & - & $0.08 \mathrm{M}$ \\
\hline$\beta G P$ & $0.2 \mathrm{M}\left(\mathrm{V}_{\mathrm{i}}=0.6 \mathrm{~mL}\right)$ & - & - & $0.16 \mathrm{M}$ \\
\hline PB & $0.1 \mathrm{M}$ & 7 & - & $0.04 \mathrm{M}$ \\
\hline SHC & $0.1 \mathrm{M}$ & $9.0 / 10.0$ & - & $0.04 \mathrm{M}$ \\
\hline
\end{tabular}

\section{2. pH Measurement, Injectability and Inversion Tube Test}

The $\mathrm{pH}$ of $\mathrm{Ch}$, Pec and GA solutions, the Ch-Pec mix and the final hydrogels was measured by test strips and monitored during the gelation process. Injection tests were performed by injecting all the hydrogel samples through a syringe equipped with a 23G needle. The behavior of the injected solutions was monitored by visual inspection. In order to evaluate the thermosensitive sol-gel transition during the inversion tube test, the solutions were injected in vials, and the fluidity/viscosity of the hydrogels was visually assessed through the inversion of the vial, at r.t. and at different time points at $37^{\circ} \mathrm{C}$.

\subsection{Rheological Analysis}

Rheological tests on Ch-Pec- $\beta$ GP, Ch-Pec-PB and Ch-Pec-SHC formulations were performed using an Anton Paar instrument (Physica MCR 301, Ostfildern, Germany) equipped with a two-plate geometry (plate diameter $25 \mathrm{~mm}$, gap distance $0.5 \mathrm{~mm}$ ) and connected to a circulating water bath. Immediately following the preparation of hydrogel samples, the variation in the storage modulus $\left(G^{\prime}\right)$ and loss modulus $\left(\mathrm{G}^{\prime \prime}\right)$ with temperature was measured, at a constant shear strain $(5 \%)$ and frequency $(1 \mathrm{~Hz})$. The temperature was increased from 5 to $50^{\circ} \mathrm{C}$ at a rate of $1{ }^{\circ} \mathrm{C} / \mathrm{min}$, and the solutions were kept at $4{ }^{\circ} \mathrm{C}$ before mixing. Each test was performed in duplicate.

\subsection{Fourier Transform Infrared (FTIR) Spectra}

FTIR spectra were obtained to understand the molecular interactions and functional group characterization. The FTIR spectra were obtained using an FT/IR-6300 type A spectrophotometer (JASCO, Easton, MD, USA) in ATR-FTIR mode. All spectra were recorded with the resolution of $4 \mathrm{~cm}^{-1}$ in the range of $400-4000 \mathrm{~cm}^{-1}$ with $100 \mathrm{scans}$. The 
measurements were performed on $\mathrm{Ch}, \mathrm{Pec}, \mathrm{Ch}-\mathrm{Pec}, \mathrm{Ch}-\mathrm{Pec}-\beta \mathrm{GP}, \mathrm{Ch}-\mathrm{Pec}-\mathrm{PB}$ and $\mathrm{Ch}-\mathrm{Pec}-$ $\mathrm{SHC}$ freeze-dried hydrogels in order to evaluate the interactions of the $\mathrm{Ch}$ amino groups with Pec, $\beta$ GP, PB and SHC.

\subsection{Swelling Test and In Vitro Stability}

The swelling ability of the hydrogels was assessed through gravimetric measurements. Briefly, after $2 \mathrm{~h}$ of incubation at $37^{\circ} \mathrm{C}$, samples were frozen at $-20^{\circ} \mathrm{C}$ and then lyophilized overnight (LIO 5P, Cinquepascal, Milan, Italy). The weight of samples was recorded using an analytical balance at the dry state, immediately after hydration in phosphate-buffered saline (PBS) and at different time points at $37^{\circ} \mathrm{C}$. The swelling ratio percentage (SR) was calculated according to the following Formula (1), where $W_{\text {dry }}$ is the initial dry weight of the hydrogel, and $\mathrm{W}_{\text {wet }}$ is the weight of the hydrogel after hydration in PBS and incubation at $37^{\circ} \mathrm{C}$ :

$$
\mathrm{SR}(\%)=\left[\left(\mathrm{W}_{\text {wet }}-\mathrm{W}_{\mathrm{dry}}\right) / \mathrm{W}_{\text {dry }}\right] \times 100
$$

The non-enzymatic degradation of the hydrogel over time was evaluated through the stability test. After $2 \mathrm{~h}$ of incubation at $37^{\circ} \mathrm{C}$, samples were weighed $(\mathrm{t}=0)$, and the weight was then monitored at different incubation times at $37^{\circ} \mathrm{C}$ in PBS. The percentage of weight loss (WL) was calculated according to the following Formula (2), where $\mathrm{W}_{0}$ is the initial weight of the hydrogel at $t=0$ after thermal gelation at $37^{\circ} \mathrm{C}$, and $\mathrm{W}_{\mathrm{i}}$ is the weight of the hydrogel after its hydration in PBS at $37^{\circ} \mathrm{C}$ at the different selected time points:

$$
\mathrm{WL}(\%)=\left[\left(\mathrm{W}_{0}-\mathrm{W}_{\mathrm{i}}\right) / \mathrm{W}_{0}\right] \times 100
$$

\subsection{Morphological Analysis}

The porous structure of the hydrogels was observed by scanning electron microscopy (SEM) (Zeiss Sigma 300 VP FE-SEM, Carl Zeiss AG, Oberkochen, Germany). After $2 \mathrm{~h}$ of incubation at $37^{\circ} \mathrm{C}$, samples were frozen for at least $2 \mathrm{~h}$ at $-20{ }^{\circ} \mathrm{C}$ and then freeze dried overnight. Samples were sectioned, gold sputtered and then observed under an SEM microscope at different magnifications. Finally, the measurement of the hydrogel pore diameter was statistically evaluated using ImageJ software (ImageJ bundled with 64-bit Java 1.8.0_172, NIH). Five SEM images (magnification $5 \times$ ) were analyzed for $\mathrm{Ch}$ Pec- $\beta$ GP, Ch-Pec-PB and Ch-Pec-SHC samples, measuring the diameter as an average of two measurements for each pore, with a total of approximately 250 pores per sample.

\subsection{Compression Test}

To evaluate the hydrogel stiffness, hydrogel samples underwent an unconfined compression test. Briefly, samples were tested after $2 \mathrm{~h}$ of incubation at $37^{\circ} \mathrm{C}$; initial diameter and thickness were recorded, and then the sample was loaded between two impermeable and non-lubricated compression plates and tested in compression in "wet" conditions at r.t. using a universal uniaxial machine (ZwickiLine $1 \mathrm{kN}$, Zwick Roell, Kennesaw, GA, USA), equipped with a $10 \mathrm{~N}$ load cell, up to $40 \%$ deformation and with a displacement velocity of $2 \mathrm{~mm} / \mathrm{min}$. The average Young modulus (E) was calculated as the slope of the linear part of the stress-strain curves at low strain values (0-5\%) for each hydrogel formulation with and without DMEM. The respective mean values were compared with each other $(n=4)$.

\subsection{Cell Culture}

Colorectal carcinoma cells (HCT 116, ATCC CCL-247, LGC Standards, Milan, Italy) were cultured in DMEM with $4.5 \mathrm{gL}^{-1}$ glucose and sodium pyruvate without L-glutamine supplemented with $2 \mathrm{mM}$ L-glutamine, 10\% Fetal Bovine Serum (FBS), $100 \mathrm{U} \mathrm{mL}^{-1}$ penicillin and $100 \mu \mathrm{g} \mathrm{mL}^{-1}$ streptomycin. Cells were incubated at $37{ }^{\circ} \mathrm{C}$ with $95 \%$ of humidity and $5 \%$ of carbon dioxide $\left(\mathrm{CO}_{2}\right)$, and $0.05 \%$ Trypsin-Ethylenediaminetetraacetic acid (Trypsin-EDTA 1X) was used regularly to pass cells every $2-3$ days until $90 \%$ confluence was reached. 


\subsection{Analysis of Cell Encapsulation in Hydrogels by Nucleus Staining}

HCT 116 cell encapsulation in the hydrogel formulations ( $\beta$ GP, PB, SHC) was evaluated using a Hoechst 33342 fluorescent stain for nuclei (NucBlue Live ReadyProbes Reagent, Thermo Fischer Scientific, Monza, Italy). Briefly, $3 \mathrm{~mL}$ of complete DMEM with 6 drops of reagent solution was prepared. After preliminary tests, a density of 2 million cells per $\mathrm{mL}$ of hydrogel was chosen for encapsulation, by gently mixing the cell suspension into the hydrogel solution. Two million cells, resuspended in $166 \mu \mathrm{L}$ of complete DMEM, were encapsulated in $1 \mathrm{~mL}$ of hydrogel. Then, $100 \mu \mathrm{L}$ spots of HCT 116 cell-embedded hydrogel were incubated at $37^{\circ} \mathrm{C} 5 \% \mathrm{CO}_{2}$. Cell encapsulation within the hydrogels and early biocompatibility assessment were evaluated after $24 \mathrm{~h}$ according to the following protocol. Briefly, once the encapsulation was carried out, $1 \mathrm{~mL}$ of DMEM distributed in the wells of a multiwell was removed and washed with PBS, and $300 \mu \mathrm{L}$ of DMEM reagent was introduced. The samples were incubated for $2 \mathrm{~h}$ at $37^{\circ} \mathrm{C}$ and observed under a fluorescence microscope (EVOS M7000, Thermo Fisher Scientific, Monza, Italy). Similarly, we assessed the late biocompatibility of the hydrogel systems after 21 days of culture by optical microscopy. Z-stack analysis was performed on Ch-Pec- $\beta$ GP samples at different magnifications (196 slices at $10 \times, 92$ slices at $40 \times$ ), with a step size of $2 \mu \mathrm{m}$.

\subsection{Statistical Analysis}

All experiments, unless differently specified, were performed in triplicate, and the results are reported as the mean \pm standard deviation. Data analysis and graphing were performed with Microsoft Excel 2019. Regarding the compression tests, GraphPad Prism software (v. 8.4.2) was employed to perform statistical analysis, using one-way ANOVA analysis.

\section{Results}

In the present study, a novel injectable thermosensitive hybrid hydrogel with $\mathrm{Ch}$ and Pec was developed (Figure 1). Three weak bases, namely, $\beta$ GP, PB and SHC, were tested as GA. All of them, once added to the Ch-Pec mix, allowed forming a stable chitosan network incorporating Pec inside at $37^{\circ} \mathrm{C}$, thus originating a semi-interpenetrating polymer network (semi-IPN). Preliminary tests (data not shown) allowed selecting the best GA concentrations able to increase the acidic $\mathrm{pH}$ of the $\mathrm{Ch}-\mathrm{Pec}$ mix to the physiological value of 7.4 and to induce the sol-gel transition at $37^{\circ} \mathrm{C}$. The different hydrogel formulations were physicochemically characterized, and a preliminary biological characterization was performed to assess the capability of the systems to embed cells for 3D in vitro culture.

\section{Chitosan}

\section{Pectin}

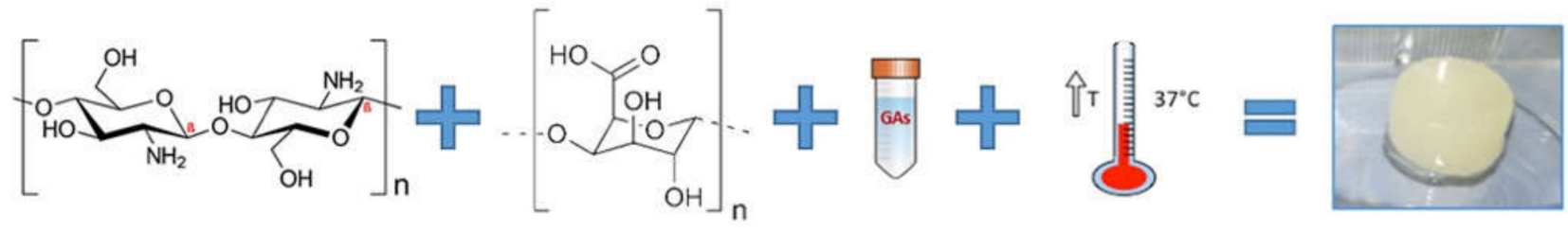

Figure 1. Schematic of the temperature-induced gelation system of chitosan and pectin-based hydrogels.

\section{1. pH Measurement, Injectability and Inversion Tube Test}

The three GA solutions, $\beta$ GP, PB and SHC, were alternately added in appropriate and optimized concentrations to the Ch-Pec mix, and the different formulations tested, with or without the addition of cell culture medium (DMEM), are shown in Table S1. In Table 1, the final polymer and GA solution concentration and the $\mathrm{pH}$ values of gelling agents, initial polymer solutions and final hydrogels after $2 \mathrm{~h}$ at $37^{\circ} \mathrm{C}$ are reported. All hydrogel formulations, despite the initial acidic $\mathrm{pH}$ values of the polymer solutions, reached a $\mathrm{pH}$ value of 7.4 immediately after the GA and DMEM addition, which was used to simulate 
cell encapsulation. A summary of three hydrogel formulations' behavior in terms of injectability and sol-gel transition is shown in Table S2. All prepared hydrogel formulations were injectable at r.t., through a G23 needle (Videos S1-S3). To evaluate the thermally induced sol-gel transition, inversion tube tests were performed (Figure S1). Although the three formulations could not easily flow at r.t. because of their high viscosity, the increase in the temperature to a physiological value was a sine qua non to induce the sol-gel transition. Indeed, without incubation for $2 \mathrm{~h}$ at $37^{\circ} \mathrm{C}$, a stable gel state could not be achieved, confirming that gelation was temperature-mediated.

\subsection{Rheological Analysis}

The rheological properties of the Ch-Pec- $\beta \mathrm{GP}, \mathrm{Ch}-\mathrm{Pec}-\mathrm{PB}$ and $\mathrm{Ch}-\mathrm{Pec}-\mathrm{SHC}$ hydrogel formulations were studied by heating samples from 5 to $50{ }^{\circ} \mathrm{C}$ at a rate of $1{ }^{\circ} \mathrm{C} / \mathrm{min}$, at a constant shear strain and frequency. The temperature dependence of the hydrogel storage modulus $\left(G^{\prime}\right)$ and loss modulus $\left(G^{\prime \prime}\right)$ is reported in Figure 2. Upon heating from 5 to $50^{\circ} \mathrm{C}$, the temperature at which $G^{\prime}$ and $G^{\prime \prime}$ rapidly increase and the slope of this increase provide an indication of the temperature of the incipient gelation [23]. As it can be observed in the diagrams in Figure 2, $\mathrm{G}^{\prime}$ and $\mathrm{G}^{\prime \prime}$ increased rapidly in all three hydrogel formulations at a temperature of about $37^{\circ} \mathrm{C}$. In Ch-Pec- $\beta$ GP hydrogels, the two moduli present an abrupt increase at the physiological temperature that is, conversely, less sharp and sudden in the $\mathrm{Ch}-\mathrm{Pec}-\mathrm{PB}$ and $\mathrm{Ch}-\mathrm{Pec}-\mathrm{SHC}$ systems, which present a broader temperature gelation range.
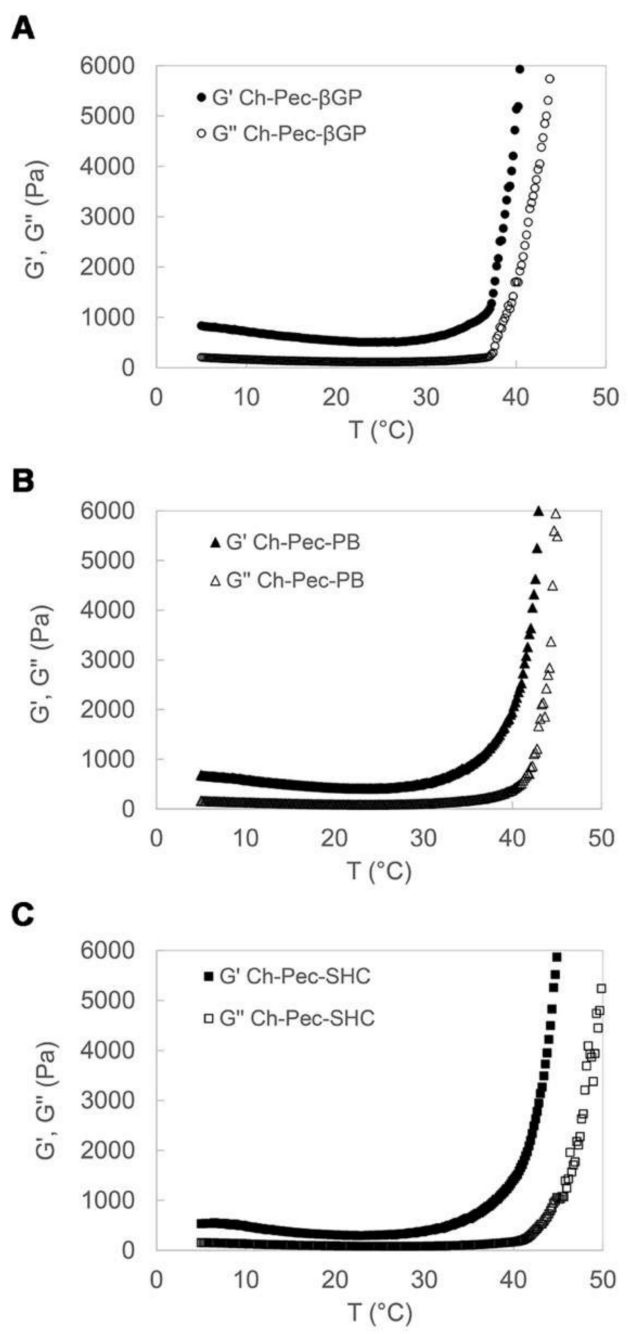

Figure 2. Temperature dependence of Ch-Pec- $\beta$ GP (A), Ch-Pec-PB (B) and Ch-Pec-SHC (C) hydrogel storage modulus $\left(\mathrm{G}^{\prime}\right)$ and loss modulus $\left(\mathrm{G}^{\prime \prime}\right)$, upon heating from 5 to $50^{\circ} \mathrm{C}$ at a rate of $1{ }^{\circ} \mathrm{C} / \mathrm{min}$. 


\subsection{FT-IR Analysis}

Figure 3A shows IR spectra of $\mathrm{Ch}, \mathrm{Pec}$ and $\mathrm{Ch}-\mathrm{Pec}$ mixing. All spectra exhibit a strong and broad nonsymmetric band at about $3430 \mathrm{~cm}^{-1}$ that results from the overlapping of the $\mathrm{O}-\mathrm{H}$ and $\mathrm{N}-\mathrm{H}$ stretching vibrations of the functional groups engaged in the hydrogen bonds. Two bands at 1740 and $1610 \mathrm{~cm}^{-1}$ in the pectin spectrum are attributed to esterified and nonesterified carboxyl groups, respectively [15]. Characteristic peaks of chitosan are observed at the $1633 \mathrm{~cm}^{-1}$ peak of amide I ( $\mathrm{C}=\mathrm{O}$ band), and at the $1535 \mathrm{~cm}^{-1}$ amide II band [26]. When chitosan and pectin were mixed, shifting to lower wavenumber values for amide I $\left(1624 \mathrm{~cm}^{-1}\right)$ and amino groups $\left(1526 \mathrm{~cm}^{-1}\right)$ was detected in the spectrum of Ch-Pec. Further slight variation in the stretching frequency was noticed upon the addition of salts into the system (Figure 3B).

A

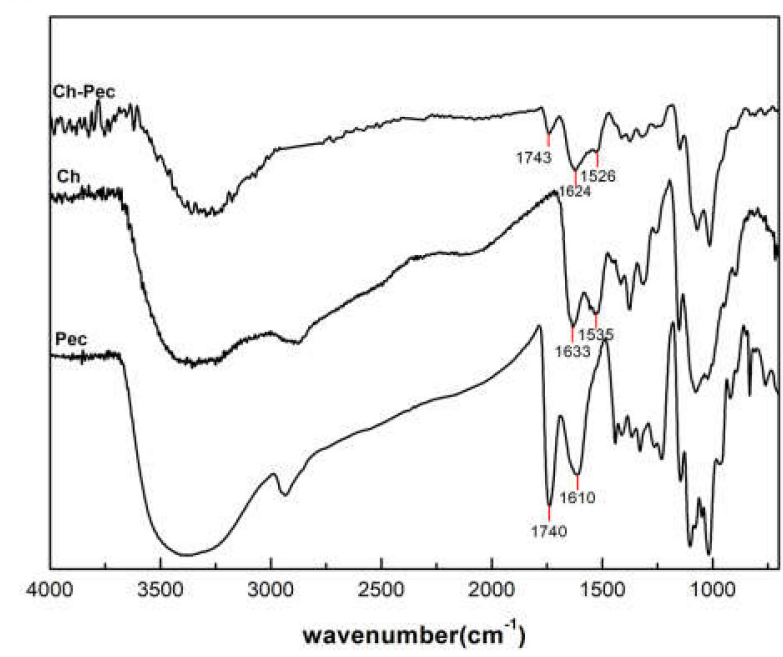

B

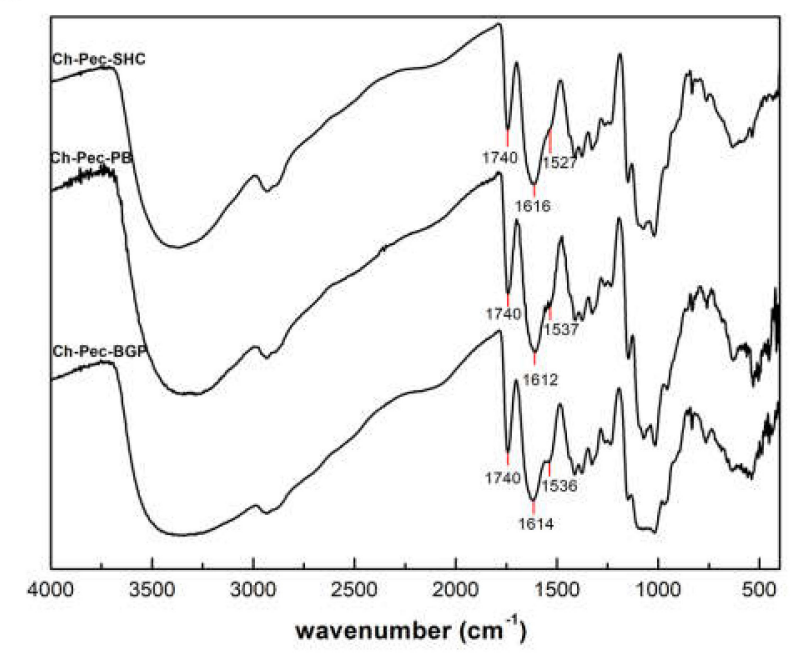

Figure 3. IR spectra of $\mathrm{Ch}$, Pec and Ch-Pec mixing (A). IR spectra of Ch-Pec mixing with salts ( $\beta G P, P B$ and SHC) (B).

\subsection{Swelling Test and In Vitro Stability}

Swelling and stability tests were performed on the hydrogel prepared using the three different GAs, with or without the addition of DMEM. The swelling test up to 21 days of incubation at $37^{\circ} \mathrm{C}$ (Figure $4 \mathrm{~A}-\mathrm{D}$ ) shows that hydrogels present a high swelling capacity already in the first $10 \mathrm{~min}$ of incubation in PBS at $37^{\circ} \mathrm{C}$. The $\beta \mathrm{GP}$ formulations, with and without DMEM, present a comparable trend and a swelling ratio of around $2000 \%$. The sample with PB shows a lower swelling capacity, which increases with the addition of DMEM. On the contrary, in the SHC sample, the addition of DMEM reduces the swelling ability. Generally, all samples were able to retain a high amount of water, reaching the equilibrium very fast and remaining stable for up to three weeks, except for the formulation with PB+DMEM (Figure 4D), where the degradation process began at day 7 , in accordance with the stability test results.

The stability test was performed on different hydrogel formulations with or without DMEM up to 25 days of incubation at $37^{\circ} \mathrm{C}$, as shown in (Figure $5 \mathrm{~A}, \mathrm{~B}$ ). All systems were stable in weight up to 7 days, and the addition of DMEM induced a decrease in the sample stability, promoting a rapid sample degradation in some cases (such as PB+DMEM and SHC+DMEM). Among all the formulations, the $\beta$ GP sample was the most stable over time, showing the best swelling ability.

\subsection{Morphological Analysis}

The structure of the different hydrogel formulations, with and without DMEM addition, was studied by SEM and optical microscopy. As shown in Figure 6 and Figure S2, the morphological analysis at different magnifications showed that all samples presented an open and highly interconnected pore structure. The analysis of the acquired images 
(Figure 7) allowed estimating the pore diameter, whose average value was about $220 \mu \mathrm{m}$, with comparable values among the three formulations. The $\beta$ GP and SHC formulations showed similar results between the +DMEM and -DMEM formulations, while PB samples showed a slight decrease in pore diameter, though not significant, in the formula with DMEM.
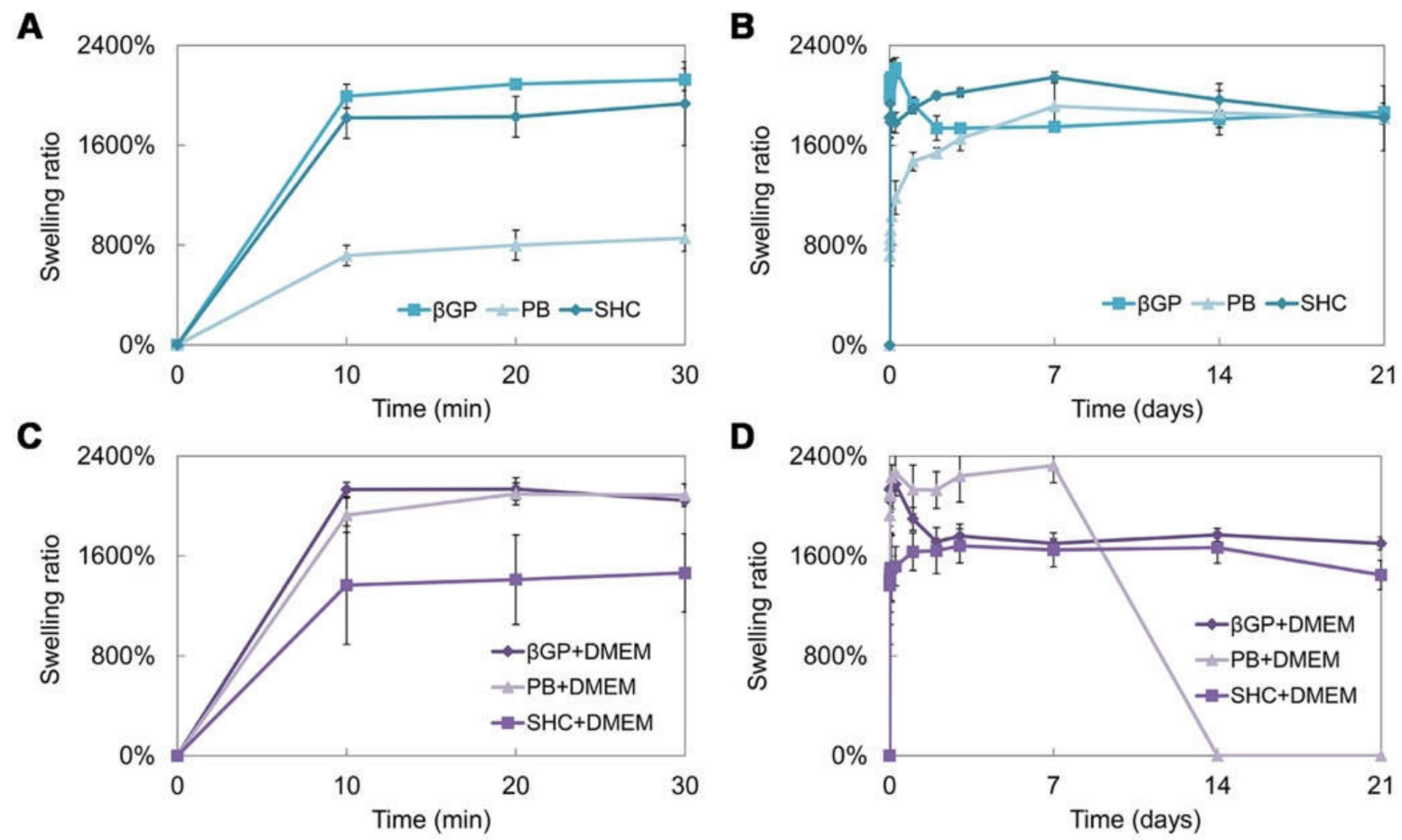

Figure 4. Swelling ratio of the three hydrogel formulations ( $\beta$ GP, PB, SHC) without DMEM in the first 30 min (A) and after 21 days of incubation in PBS at $37^{\circ} \mathrm{C}(\mathbf{B})$, and with DMEM in the first $30 \mathrm{~min}(\mathbf{C})$ and after 21 days of incubation in PBS at $37^{\circ} \mathrm{C}(\mathbf{D})$.

\section{A}

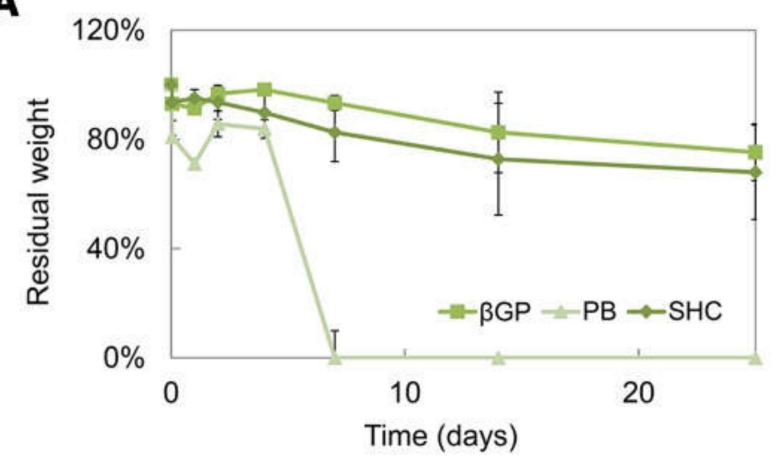

B

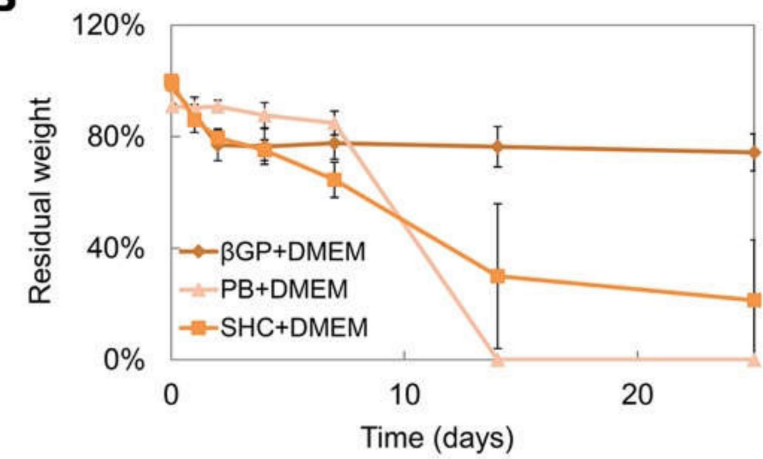

Figure 5. Residual weight percentage after 25 days of incubation in PBS at $37^{\circ} \mathrm{C}$ of the three hydrogel formulations ( $\beta$ GP-PB-SHC) without DMEM (A), and with DMEM (B). 

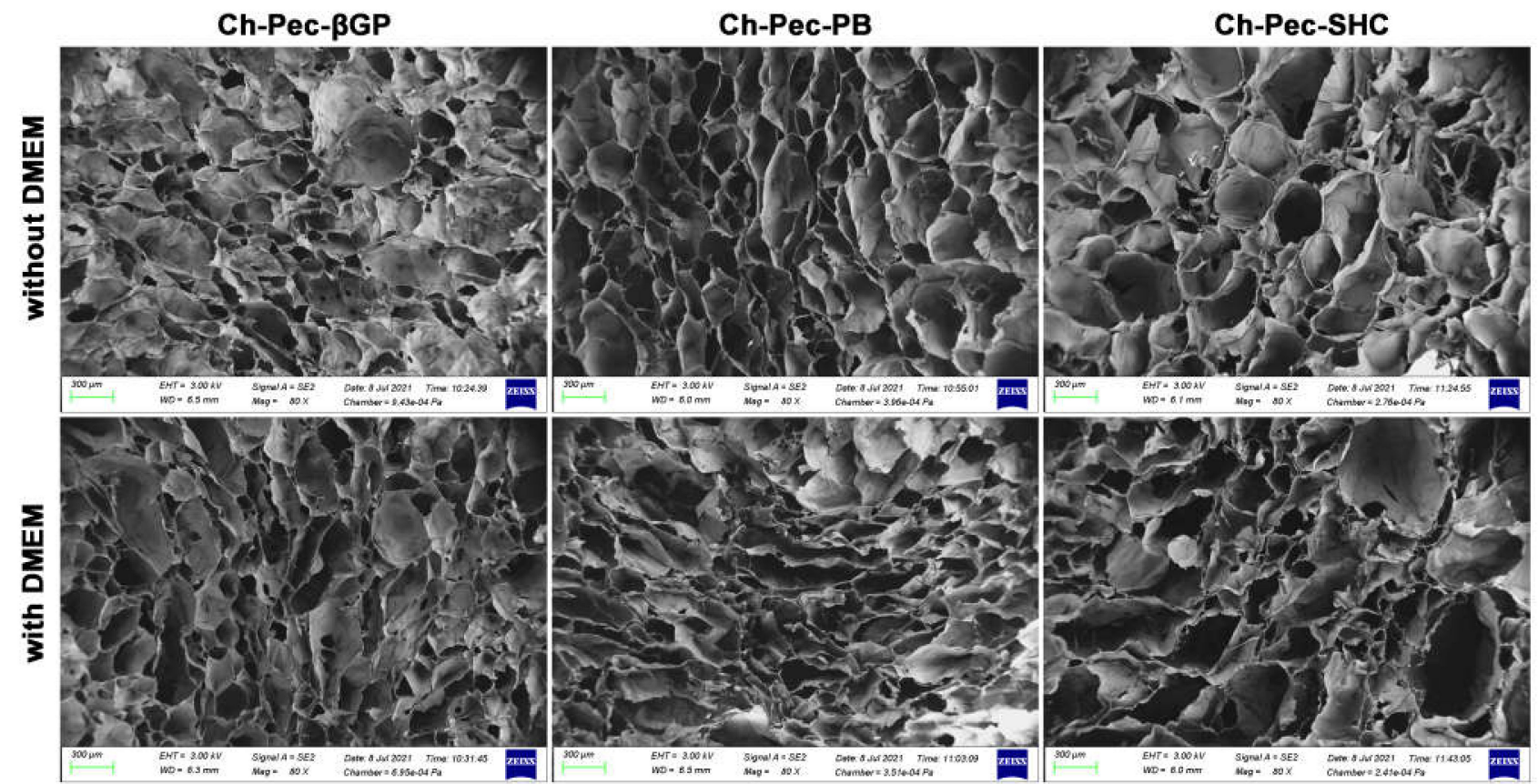

Figure 6. SEM investigation: morphological analysis of hydrogel formulations ( $\beta$ GP-PB-SHC), with and without the addition of DMEM (magnification $80 \times$, scale bar $300 \mu \mathrm{m}$ ).

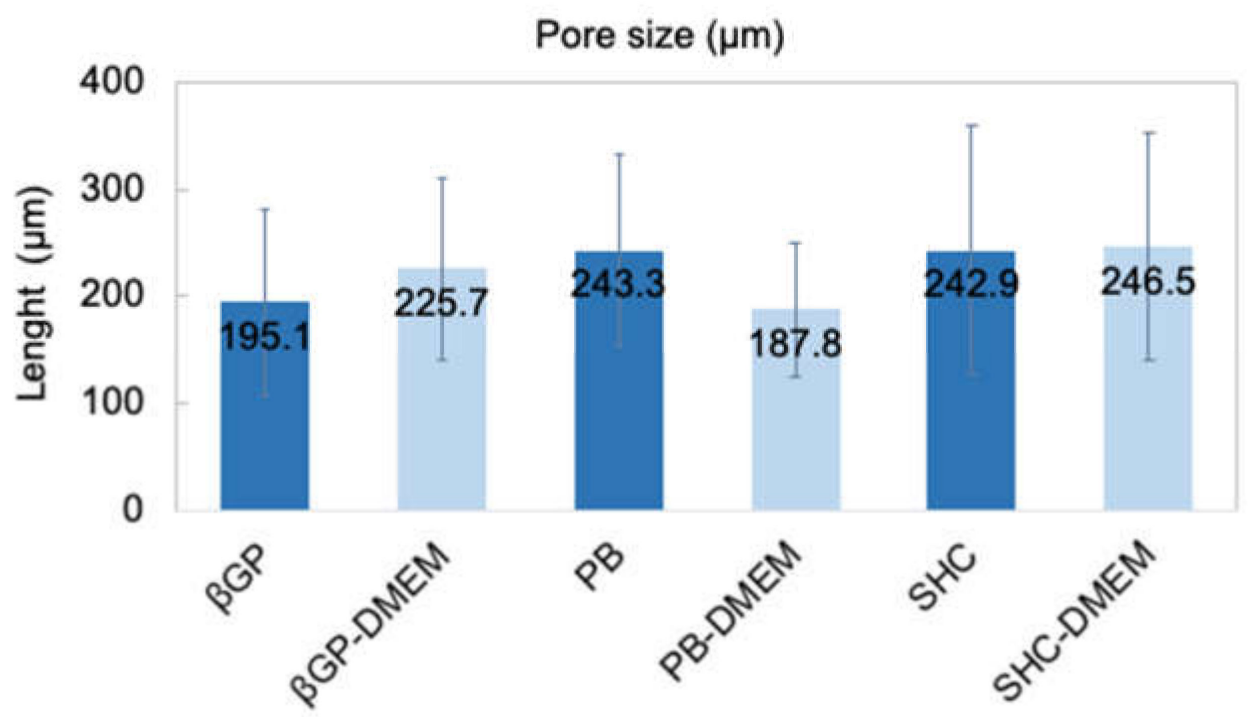

Figure 7. Average pore size of three hydrogel formulations ( $\beta$ GP-PB-SHC) with and without the addition of DMEM.

\subsection{Compression Test}

The mechanical properties of the hydrogels were evaluated through compression tests, which allowed observing that there were no significant differences between the formulations of hydrogels with and without the addition of DMEM, indicating that the amount of DMEM used was actually small enough to not alter the mechanical properties of the system. The compression test showed a very low Young modulus (between 1 and $2 \mathrm{kPa}$ ) for all the different samples without any significant difference among the hydrogel types (Figure 8). 


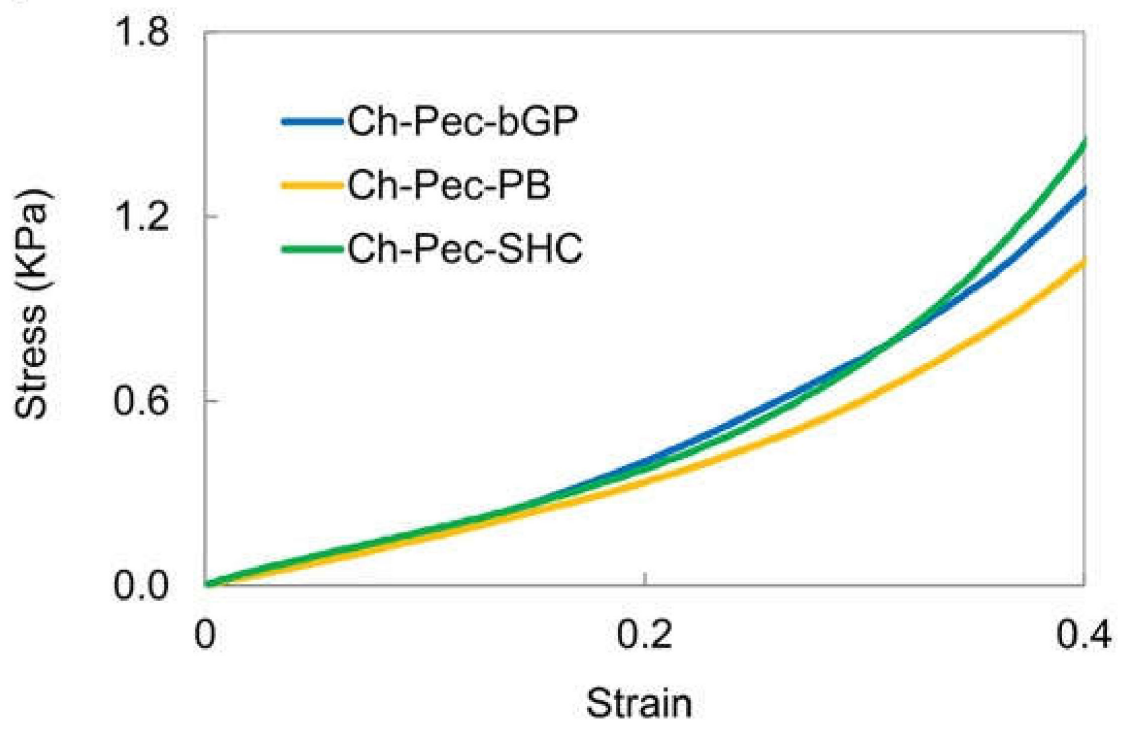

B

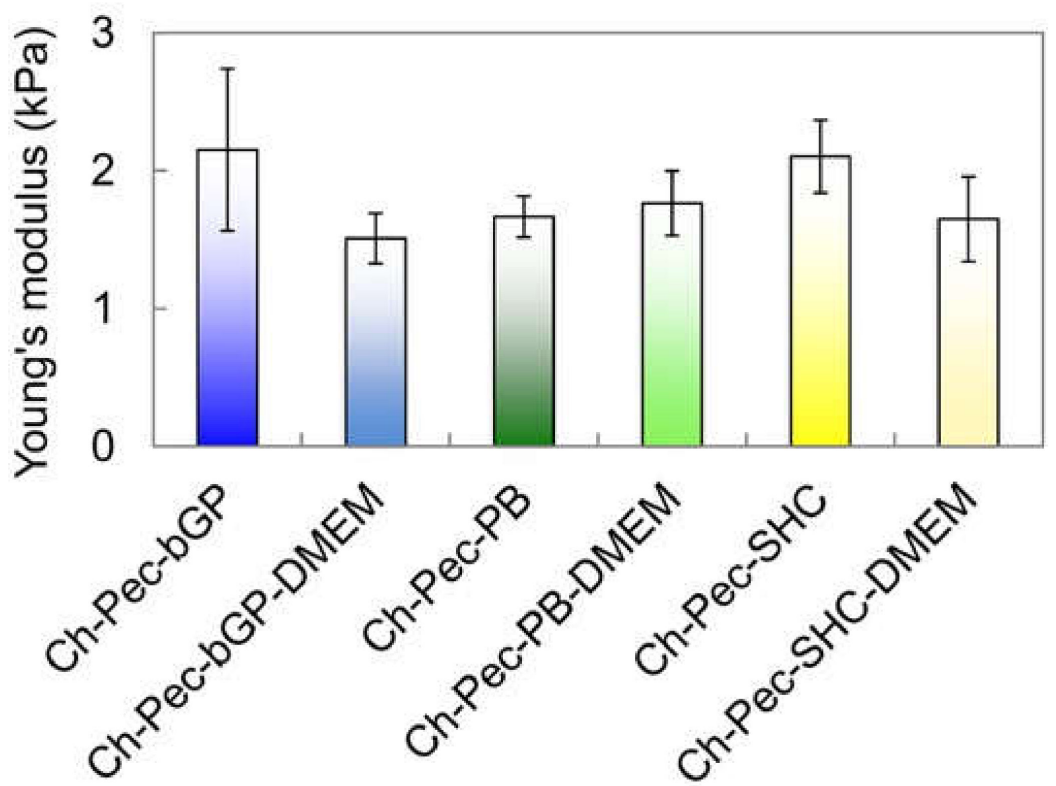

Figure 8. Compression test: (A) Stress-strain curves of the hydrogel formulations ( $\beta$ GP-PB-SHC). (B) Average values of Young's modulus for all three hydrogels with and without DMEM $(n=3)$.

\subsection{Cell Encapsulation in Hydrogels by Nucleus Staining}

To evaluate the morphology and encapsulation of HCT 116 cells throughout the samples, the cell-laden hydrogels were stained for nuclei after $24 \mathrm{~h}$ of culture and observed by fluorescence microscopy (Figure 9A). HCT 116 cells spread over the entire volume of all the hydrogels, indicating that this method allowed the homogeneous encapsulation of the cells through the hydrogel samples. However, the cells appeared significantly more numerous in Ch-Pec- $\beta$ GP than the other two formulations. Cell growth was analyzed after 21 days of culture to assess the late biocompatibility of the hydrogel systems. We noticed the formation of cell aggregates (spheroids) in all the formulations (Figure 9B). Overall, Ch-Pec- $\beta$ GP displayed a higher number of spheroids throughout the sample (Figure $9 \mathrm{C}$, Videos S4 and S5). 


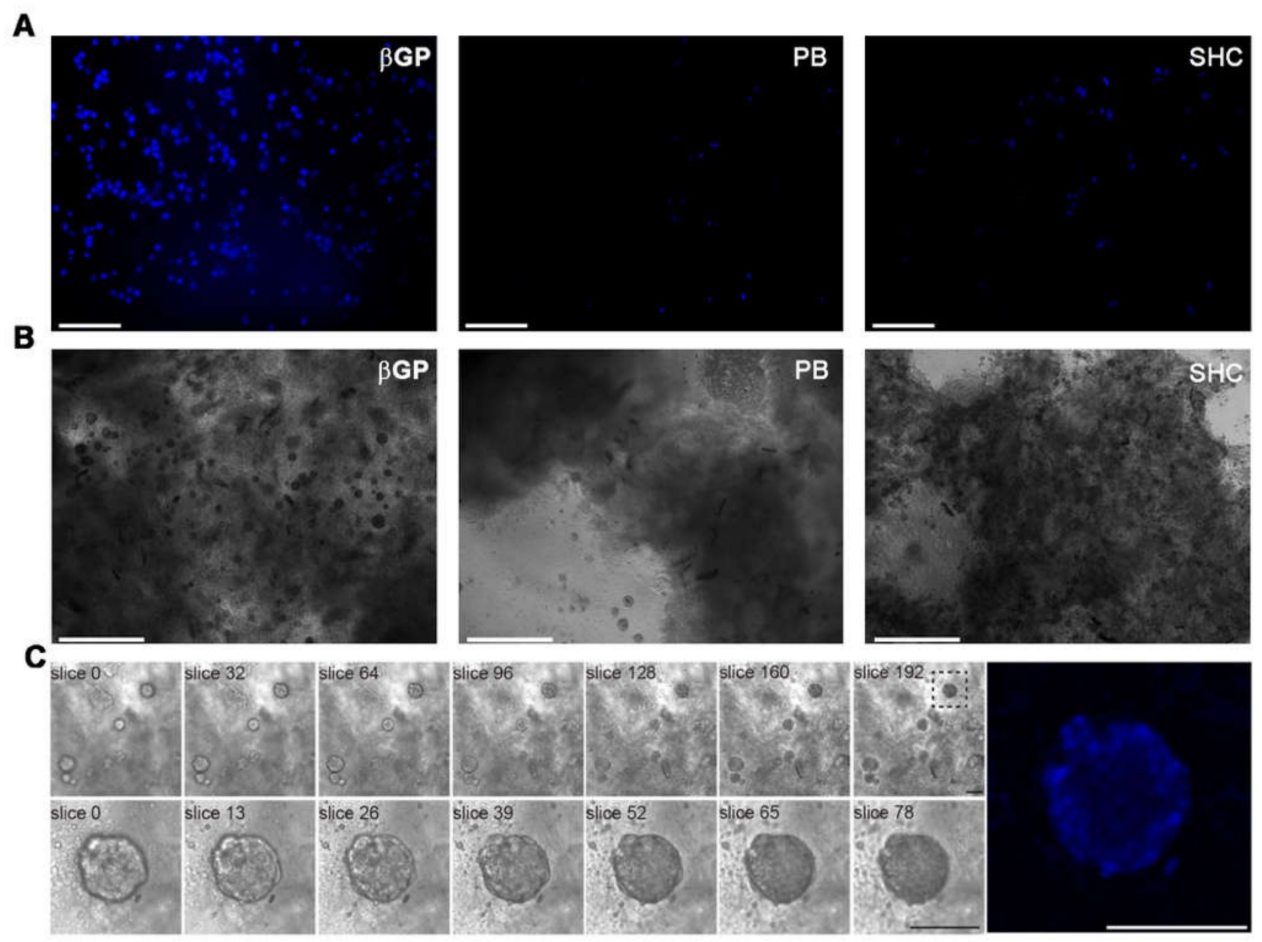

Figure 9. (A) Fluorescence microscopy investigation at $24 \mathrm{~h}$ of culture of cell-laden Ch-Pec hydrogels formed in the presence of different GAs. (B) Optical investigation of spheroids in Ch-Pec hydrogels after 21 days of culture. (C) Z-stack analysis at different magnifications of spheroids in Ch-Pec- $\beta$ GP hydrogels after 21 days of culture (scale bars: $100 \mu \mathrm{m}$ ).

\section{Discussion}

In this study, we aimed at developing a chitosan/pectin hydrogel system suitable for cell embedding and culturing, meeting, therefore, some fundamental chemico-physical requirements, such as (i) a physiological $\mathrm{pH}$, (ii) injectability at r.t. and (iii) ability to gel at the physiological temperature, i.e., $37^{\circ} \mathrm{C}$. Several hydrogels with chitosan and pectin have been proposed in the literature; however, they are usually in the gel state at r.t. and in the sol state at high temperatures used to solubilize the two polymers $\left(60\right.$ to $\left.97^{\circ} \mathrm{C}\right)$, conditions not suitable for cell viability [14-16,27-34]. To overcome the limits of the chitosan/pectin systems reported in the literature, not compatible with cell embedding applications, in the present study, we decided to exploit the well-known ability of chitosan solution to gel at $37{ }^{\circ} \mathrm{C}$ thanks to the addition of weak bases such as $\beta \mathrm{GP}$, in order to induce the formation of a chitosan hydrogel network that incorporates pectin inside, giving rise to a semi-IPN. Here, besides $\beta$ GP, PB and SHC were also tested as potential gelling agents able to induce the thermal sol-gel transition of the Ch-Pec mix. All the systems ( $\beta$ GP, PB and $\mathrm{SHC}$ ) presented a $\mathrm{pH}$ suitable for cell viability, reaching a $\mathrm{pH}$ value of 7.4 immediately after mixing with GAs, resulting in being injectable at r.t., with a sol-gel transition at $37^{\circ} \mathrm{C}$. Although they were injectable, in the tube inversion test, all the formulations could not easily flow already at r.t. due to their high viscosity. However, a stable gel state could be achieved only by increasing the temperature to $37^{\circ} \mathrm{C}$, demonstrating that without heating, gelling did not occur. Moreover, the thermosensitive behavior of the hydrogel was confirmed by rheological analysis performed on the Ch-Pec mix immediately after the salt solution addition. The rheological results highlight the salt-mediated thermosensitive gelation of the systems, showing a sudden and abrupt increase in the storage and loss moduli of all the hydrogel formulations. The Ch-Pec- $\beta$ GP formulation took place in the narrowest range of temperature, with respect to the PB and SHC system.

From the FTIR analysis, we witnessed a shifting to lower wavenumber values for amide I $\left(1624 \mathrm{~cm}^{-1}\right)$ and amino groups $\left(1526 \mathrm{~cm}^{-1}\right)$ in Ch-Pec systems, indicating a change 
in the surroundings of these groups due to an ionic interaction of protonated amino groups of chitosan and the carboxyl groups of pectin [35-37]. With the addition of $\beta$ GP, PB and SHC salts, a further slight variation in the stretching frequency was observed, likely due to amine group deprotonation [38]. According to Assad et al. [22], in fact, using SHC leads to a neutralization of the Ch chains [39], while using PB or $\beta$ GP may hinder some $\mathrm{NH}^{2+}$ groups within the chain network after the interaction between protonated $\mathrm{Ch}$ and negatively charged PB or $\beta$ GP [25].

The three hydrogels reached very fast (less than $30 \mathrm{~min}$ ) and very high swelling values (between 1500 and 2000\%) in both formulations with and without DMEM, faster and higher values than similar $\mathrm{Ch}$-Pe systems proposed by other authors that reported lower swelling ratio values (about 370\% [27], 150-200\% [40] or slower [15]) [14,29,31,41]. Regarding the in vitro stability, tested up to 25 days, hydrogels without DMEM were stable up to 25 days, except for the Ch-Pec-PB samples that completely degraded after 7 days. The addition of DMEM, used to simulate the cell delivery within the system, induced a decrease in the sample stability and, in the Ch-Pec-PB-DMEM and Ch-Pec-SHC-DMEM hydrogels, favored a faster degradation. Among all formulations, samples with $\beta$ GP resulted in being the most stable, and samples with PB resulted in being the weakest. Morphological analysis performed by SEM allowed analyzing the structure of the hydrogels, which presented an open and highly interconnected pore structure and a pore diameter value in the range of 180-250 $\mu \mathrm{m}$. The Ch-Pec-PB-DMEM formulation showed the smallest pores probably because of the weak structure that partially collapsed.

The performed mechanical characterization by means of compression tests highlighted a very low Young modulus (between 1 and $2 \mathrm{kPa}$ ) for all hydrogel formulations tested, a value that falls within the stiffness range of the ECM of soft biological tissues, such as the nervous tissue, whose matrix in healthy conditions presents a stiffness between 0.1 and $1 \mathrm{kPa}$ [42], or the healthy colon tissue, between 2 and $5 \mathrm{kPa}$ [43]. Furthermore, no significant differences were evidenced between the hydrogel formulations with and without the addition of DMEM, indicating that the amount of DMEM introduced into the system to load the cells inside did not induce any change in the mechanical properties of the hydrogel. Our findings are in agreement with those reported by Bombaldi de Souza and colleagues in 2020 [44], where the elastic modulus of chitosan and pectin tubular scaffolds was lower than $2 \mathrm{kPa}$ in the strain range between 5 and $20 \%$, although this value was measured performing a tensile testing test. Unfortunately, to the best of our knowledge, there are no $\mathrm{Ch}-\mathrm{Pec}$ systems in the literature characterized by compressive tests. However, our values are close to those reported for other hydrogel systems [24,45] and are especially in the range of several human soft tissues [46].

Finally, HCT 116 cells were encapsulated in the different formulations to assess their potential application as cell-embedding hydrogels in 3D in vitro models. Cells were successfully inserted into all the formulations, and the following nuclei staining analysis at $24 \mathrm{~h}$ of culture demonstrated the superiority of Ch-Pec- $\beta$ GP as a cell-embedding system. In fact, in the Ch-Pec- $\beta$ GP hydrogel, cells appeared numerous and homogenously embedded within the matrix in comparison to the other formulations. This is likely due to the presence of a more stable polymer network facilitated by $\beta G P$, as also confirmed by the physicochemical results. However, all the formulations successfully led to the formation of cell aggregates (spheroids) after 21 days of culture. This phenomenon was also reported in other hydrogel systems embedding HCT 116 cells [47-49]. These findings highlight the suitability of our systems as an artificial 3D matrix for in vitro models, with the $\beta$ GP-based formulation confirming its superiority over the others for long-term cell culture.

Overall, the stability and mechanical results highlight that the introduction of Pec within the Ch/ $\beta$ GP system was able to originate a very soft hydrogel compared to the single-polymer network [24] without altering its stability in vitro, two difficultly co-existing characteristics, indicating that such a hybrid polymer system could be an excellent candidate as a 3D ECM analogue of very soft tissues in long-term 3D in vitro culture. 


\section{Conclusions}

In the hydrogel systems here proposed, we demonstrated that it is possible to exploit the well-known ability of $\mathrm{Ch}$ to form a stable hydrogel network with different gelling agents, namely, $\beta \mathrm{GP}, \mathrm{PB}$ and SHC, to incorporate a second polymer within the system, $\mathrm{Pec}$, and originate a salt-mediated thermosensitive $\mathrm{Ch}-\mathrm{Pec}$ hydrogel. The developed systems reached a sol-gel transition at $37^{\circ} \mathrm{C}$, had a physiological $\mathrm{pH}$ compatible with cell embedding, were stable over a long time ( 25 days in culture conditions), were able to retain a high amount of water and presented mechanical properties in the range of soft biological tissues. Finally, preliminary cell encapsulation tests evidenced the ability of the Ch-Pec- $\beta$ GP system to host cells that resulted in being homogenously dispersed within the matrix. All the here reported Ch-Pec- $\beta$ GP hydrogel features make it an ideal candidate as an ECM analogue for long 3D in vitro cell culture.

Supplementary Materials: The following are available online at https:/ / www.mdpi.com/article/10 .3390 / polym13162674/s1, Figure S1 (Inversion tube test) and Figure S2 (Scanning electron micrographs), Table S1 (Hydrogel formulations with different GAs) and Table S2 (Schematal representation of inversion tube test and injection test), Videos S1-S3 (Injection tests with different GAs) and S4-S5 (Z-stack analyses).

Author Contributions: Conceptualization, F.G.; methodology, G.M., A.P., F.S., R.R.; hydrogel preparation, video recording, picture acquisition, swelling and stability test, G.M.; FTIR and SEM analysis and data analysis, F.S.; cell encapsulation and biological investigation, G.M., R.R.; compression tests, result analysis, F.G.; supervision of cell study, A.P.; writing—original draft preparation, G.M.; writing-review and editing, F.G., A.P.; supervision, F.G., A.P.; funding acquisition, G.G., A.P.; project administration, G.G. All authors have read and agreed to the published version of the manuscript.

Funding: This research was funded by "Tecnopolo per la medicina di precisione" (TecnoMed Puglia)-Regione Puglia: DGR n.2117 del 21/11/2018, CUP: B84I18000540002 and "Tecnopolo di Nanotecnologia e Fotonica per la medicina di precisione" (TECNOMED)-FISR/MIUR-CNR: delibera CIPE n.3449 del 7-08-2017, CUP: B83B17000010001. A.P. and F.G. gratefully acknowledge the support from the European Union's Horizon 2020 research and innovation programme under grant agreement No. 953121 (FLAMIN-GO).

Institutional Review Board Statement: Not applicable.

Informed Consent Statement: Not applicable.

Conflicts of Interest: The authors declare no conflict of interest.

\section{References}

1. Aguado, B.A.; Grim, J.C.; Rosales, A.M.; Watson-Capps, J.J.; Anseth, K.S. Engineering precision biomaterials for personalized medicine. Sci. Transl. Med. 2018, 10, eaam8645. [CrossRef]

2. Devarasetty, M.; Dominijanni, A.; Herberg, S.; Shelkey, E.; Skardal, A.; Soker, S. Simulating the human colorectal cancer microenvironment in 3D tumor-stroma co-cultures in vitro and in vivo. Sci. Rep. 2020, 10, 9832. [CrossRef] [PubMed]

3. Li, Z.L.; Wang, Z.J.; Wei, G.H.; Yang, Y.; Wang, X.W. Changes in extracellular matrix in different stages of colorectal cancer and their effects on proliferation of cancer cells. World J. Gastrointest. Oncol. 2020, 12, 267-275. [CrossRef] [PubMed]

4. Langhans, S.A. Three-Dimensional in Vitro Cell Culture Models in Drug Discovery and Drug Repositioning. Front. Pharmacol. 2018, 9, 6. [CrossRef]

5. Piccoli, M.; D’Angelo, E.; Crotti, S.; Sensi, F.; Urbani, L.; Maghin, E.; Burns, A.; De Coppi, P.; Fassan, M.; Rugge, M.; et al. Decellularized colorectal cancer matrix as bioactive microenvironment for in vitro 3D cancer research. J. Cell. Physiol. 2018, 233, 5937-5948. [CrossRef] [PubMed]

6. Zanoni, M.; Cortesi, M.; Zamagni, A.; Arienti, C.; Pignatta, S.; Tesei, A. Modeling neoplastic disease with spheroids and organoids. J. Hematol. Oncol. 2020, 13, 97. [CrossRef] [PubMed]

7. Pampaloni, F.; Reynaud, E.G.; Stelzer, E.H. The third dimension bridges the gap between cell culture and live tissue. Nat. Rev. Mol. Cell Biol. 2007, 8, 839-845. [CrossRef]

8. Reidy, E.; Leonard, N.A.; Treacy, O.; Ryan, A.E. A 3D View of Colorectal Cancer Models in Predicting Therapeutic Responses and Resistance. Cancers 2021, 13, 227. [CrossRef]

9. Hoffman, A.S. Hydrogels for biomedical applications. Adv. Drug Deliv. Rev. 2012, 64, 18-23. [CrossRef]

10. Thiele, J.; Ma, Y.; Bruekers, S.M.; Ma, S.; Huck, W.T. 25th anniversary article: Designer hydrogels for cell cultures: A materials selection guide. Adv. Mater. 2014, 26, 125-147. [CrossRef] 
11. Wieringa, P.A.; Goncalves de Pinho, A.R.; Micera, S.; van Wezel, R.J.A.; Moroni, L. Biomimetic Architectures for Peripheral Nerve Repair: A Review of Biofabrication Strategies. Adv. Healthc. Mater. 2018, 7, e1701164. [CrossRef]

12. Yang, J.; Zhang, Y.S.; Yue, K.; Khademhosseini, A. Cell-laden hydrogels for osteochondral and cartilage tissue engineering. Acta Biomater. 2017, 57, 1-25. [CrossRef] [PubMed]

13. Liu, H.; Wang, Y.; Cui, K.; Guo, Y.; Zhang, X.; Qin, J. Advances in Hydrogels in Organoids and Organs-on-a-Chip. Adv. Mater. 2019, 31, e1902042. [CrossRef]

14. Michailidou, G.; Terzopoulou, Z.; Kehagia, A.; Michopoulou, A.; Bikiaris, D.N. Preliminary Evaluation of 3D Printed Chitosan/Pectin Constructs for Biomedical Applications. Mar. Drugs 2021, 19, 36. [CrossRef] [PubMed]

15. Neufeld, L.; Bianco-Peled, H. Pectin-chitosan physical hydrogels as potential drug delivery vehicles. Int. J. Biol. Macromol. 2017, 101, 852-861. [CrossRef] [PubMed]

16. Tentor, F.R.; de Oliveira, J.H.; Scariot, D.B.; Lazarin-Bidóia, D.; Bonafé, E.G.; Nakamura, C.V.; Venter, S.A.S.; Monteiro, J.P.; Muniz, E.C.; Martins, A.F. Scaffolds based on chitosan/pectin thermosensitive hydrogels containing gold nanoparticles. Int. J. Biol. Macromol. 2017, 102, 1186-1194. [CrossRef] [PubMed]

17. Ahsan, S.M.; Thomas, M.; Reddy, K.K.; Sooraparaju, S.G.; Asthana, A.; Bhatnagar, I. Chitosan as biomaterial in drug delivery and tissue engineering. Int. J. Biol. Macromol. 2018, 110, 97-109. [CrossRef]

18. Kozen, B.G.; Kircher, S.J.; Henao, J.; Godinez, F.S.; Johnson, A.S. An alternative hemostatic dressing: Comparison of CELOX, HemCon, and QuikClot. Acad. Emerg. Med. 2008, 15, 74-81. [CrossRef]

19. Ueno, H.; Mori, T.; Fujinaga, T. Topical formulations and wound healing applications of chitosan. Adv. Drug Deliv. Rev. 2001, 52, 105-115. [CrossRef]

20. Lapomarda, A.; De Acutis, A.; Chiesa, I.; Fortunato, G.M.; Montemurro, F.; De Maria, C.; Mattioli Belmonte, M.; Gottardi, R.; Vozzi, G. Pectin-GPTMS-based biomaterial: Toward a sustainable bioprinting of 3D scaffolds for tissue engineering application. Biomacromolecules 2019, 21, 319-327. [CrossRef] [PubMed]

21. Munarin, F.; Tanzi, M.C.; Petrini, P. Advances in biomedical applications of pectin gels. Int. J. Biol. Macromol. 2012, 51, 681-689. [CrossRef] [PubMed]

22. Assaad, E.; Maire, M.; Lerouge, S. Injectable thermosensitive chitosan hydrogels with controlled gelation kinetics and enhanced mechanical resistance. Carbohydr. Polym. 2015, 130, 87-96. [CrossRef]

23. Chenite, A.; Buschmann, M.; Wang, D.; Chaput, C.; Kandani, N. Rheological characterisation of thermogelling chitosan/glycerolphosphate solutions. Carbohydr. Polym. 2001, 46, 39-47. [CrossRef]

24. Stanzione, A.; Polini, A.; La Pesa, V.; Romano, A.; Quattrini, A.; Gigli, G.; Moroni, L.; Gervaso, F. Development of Injectable Thermosensitive Chitosan-Based Hydrogels for Cell Encapsulation. Appl. Sci. 2020, 10, 6550. [CrossRef]

25. Zhou, H.Y.; Jiang, L.J.; Cao, P.P.; Li, J.B.; Chen, X.G. Glycerophosphate-based chitosan thermosensitive hydrogels and their biomedical applications. Carbohydr. Polym. 2015, 117, 524-536. [CrossRef]

26. Yasayan, G. Chitosan films and chitosan/pectin polyelectrolyte complexes encapsulating silver sulfadiazine for wound healing. $J$ Fac. Pharm. Istanb. Univ. 2020, 50, 238-245.

27. Birch, N.P.; Barney, L.E.; Pandres, E.; Peyton, S.R.; Schiffman, J.D. Thermal-Responsive Behavior of a Cell Compatible Chitosan/Pectin Hydrogel. Biomacromolecules 2015, 16, 1837-1843. [CrossRef] [PubMed]

28. Hiorth, M.; Kjøniksen, A.-L.; Knudsen, K.D.; Sande, S.A.; Nyström, B. Structural and dynamical properties of aqueous mixtures of pectin and chitosan. Eur. Polym. J. 2005, 41, 1718-1728. [CrossRef]

29. Long, J.; Etxeberria, A.E.; Nand, A.V.; Bunt, C.R.; Ray, S.; Seyfoddin, A. A 3D printed chitosan-pectin hydrogel wound dressing for lidocaine hydrochloride delivery. Mater. Sci. Eng. C 2019, 104, 109873. [CrossRef]

30. Martins, J.G.; Camargo, S.E.; Bishop, T.T.; Popat, K.C.; Kipper, M.J.; Martins, A.F. Pectin-chitosan membrane scaffold imparts controlled stem cell adhesion and proliferation. Carbohydr. Polym. 2018, 197, 47-56. [CrossRef]

31. Shitrit, Y.; Davidovich-Pinhas, M.; Bianco-Peled, H. Shear thinning pectin hydrogels physically cross-linked with chitosan nanogels. Carbohydr. Polym. 2019, 225, 115249. [CrossRef]

32. Torpol, K.; Sriwattana, S.; Sangsuwan, J.; Wiriyacharee, P.; Prinyawiwatkul, W. Optimising chitosan-pectin hydrogel beads containing combined garlic and holy basil essential oils and their application as antimicrobial inhibitor. Int. J. Food Sci. Technol. 2019, 54, 2064-2074. [CrossRef]

33. Ventura, I.; Bianco-Peled, H. Small-angle X-ray scattering study on pectin-chitosan mixed solutions and thermoreversible gels. Carbohydr. Polym. 2015, 123, 122-129. [CrossRef]

34. Zhang, H.; Cong, Y.; Osi, A.R.; Zhou, Y.; Huang, F.; Zaccaria, R.P.; Chen, J.; Wang, R.; Fu, J. Direct 3D printed biomimetic scaffolds based on hydrogel microparticles for cell spheroid growth. Adv. Funct. Mater. 2020, 30, 1910573. [CrossRef]

35. Coimbra, P.; Ferreira, P.; De Sousa, H.; Batista, P.; Rodrigues, M.; Correia, I.; Gil, M. Preparation and chemical and biological characterization of a pectin/chitosan polyelectrolyte complex scaffold for possible bone tissue engineering applications. Int. J. Biol. Macromol. 2011, 48, 112-118. [CrossRef]

36. Li, D.; Wang, S.; Meng, Y.; Guo, Z.; Cheng, M.; Li, J. Fabrication of self-healing pectin/chitosan hybrid hydrogel via Diels-Alder reactions for drug delivery with high swelling property, $\mathrm{pH}-$ responsiveness, and cytocompatibility. Carbohydr. Polym. 2021, 268, 118244. [CrossRef] [PubMed]

37. Maciel, V.B.V.; Yoshida, C.M.; Franco, T.T. Chitosan/pectin polyelectrolyte complex as a pH indicator. Carbohydr. Polym. 2015, 132, 537-545. [CrossRef] [PubMed] 
38. Takara, E.A.; Marchese, J.; Ochoa, N.A. NaOH treatment of chitosan films: Impact on macromolecular structure and film properties. Carbohydr. Polym. 2015, 132, 25-30. [CrossRef] [PubMed]

39. Liu, L.; Tang, X.; Wang, Y.; Guo, S. Smart gelation of chitosan solution in the presence of $\mathrm{NaHCO}_{3}$ for injectable drug delivery system. Int. J. Pharm. 2011, 414, 6-15. [CrossRef]

40. Bernabé, P.; Peniche, C.; Argüelles-Monal, W. Swelling behavior of chitosan/pectin polyelectrolyte complex membranes. Effect of thermal cross-linking. Polym. Bull. 2005, 55, 367-375. [CrossRef]

41. Sigaeva, N.; Vil'danova, R.; Sultanbaev, A.; Ivanov, S. Synthesis and Properties of Chitosan-and Pectin-Based Hydrogels. Colloid J. 2020, 82, 311-323. [CrossRef]

42. Wang, C.; Tong, X.; Yang, F. Bioengineered 3D brain tumor model to elucidate the effects of matrix stiffness on glioblastoma cell behavior using PEG-based hydrogels. Mol. Pharm. 2014, 11, 2115-2125. [CrossRef]

43. Nebuloni, M.; Albarello, L.; Andolfo, A.; Magagnotti, C.; Genovese, L.; Locatelli, I.; Tonon, G.; Longhi, E.; Zerbi, P.; Allevi, R. Insight on colorectal carcinoma infiltration by studying perilesional extracellular matrix. Sci. Rep. 2016, 6, 1-13. [CrossRef] [PubMed]

44. Bombaldi de Souza, F.C.; Camasão, D.B.; Bombaldi de Souza, R.F.; Drouin, B.; Mantovani, D.; Moraes, Â.M. A simple and effective approach to produce tubular polysaccharide-based hydrogel scaffolds. J. Appl. Polym. Sci. 2020, 137, 48510. [CrossRef]

45. Huang, Y.; Onyeri, S.; Siewe, M.; Moshfeghian, A.; Madihally, S.V. In vitro characterization of chitosan-gelatin scaffolds for tissue engineering. Biomaterials 2005, 26, 7616-7627. [CrossRef]

46. Guimarães, C.F.; Gasperini, L.; Marques, A.P.; Reis, R.L. The stiffness of living tissues and its implications for tissue engineering. Nat. Rev. Mater. 2020, 5, 351-370. [CrossRef]

47. Devarasetty, M.; Wang, E.; Soker, S.; Skardal, A. Mesenchymal stem cells support growth and organization of host-liver colorectal-tumor organoids and possibly resistance to chemotherapy. Biofabrication 2017, 9, 021002. [CrossRef]

48. Forsythe, S.; Mehta, N.; Devarasetty, M.; Sivakumar, H.; Gmeiner, W.; Soker, S.; Votanopoulos, K.; Skardal, A. Development of a Colorectal Cancer 3D Micro-tumor Construct Platform From Cell Lines and Patient Tumor Biospecimens for Standard-of-Care and Experimental Drug Screening. Ann. Biomed. Eng. 2020, 48, 940-952. [CrossRef]

49. Fiorica, C.; Palumbo, F.S.; Pitarresi, G.; Puleio, R.; Condorelli, L.; Collura, G.; Giammona, G. A hyaluronic acid/cyclodextrin based injectable hydrogel for local doxorubicin delivery to solid tumors. Int. J. Pharm. 2020, 589, 119879. [CrossRef] 